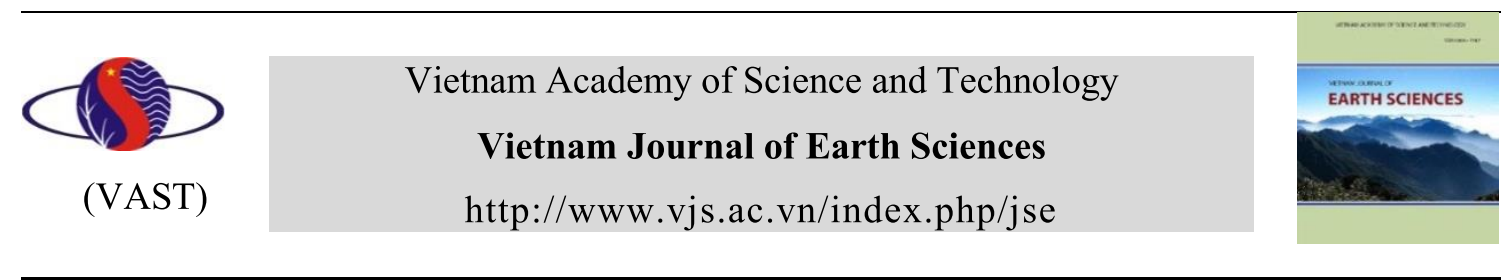

\title{
Using Artificial Neural Network (ANN) for prediction of soil coefficient of consolidation
}

\author{
Binh Thai Pham¹, Sushant K. Singh², Hai-Bang Ly* \\ ${ }^{1}$ University of Transport Technology, Hanoi 100000, Vietnam \\ ${ }^{2}$ Artificial Intelligence \& Analytics, Healthcare and Life Science, Virtusa Corporation, New York, U.S.A.
}

Received 01 March 2020; Received in revised form 17 April 2020; Accepted 22 June 2020

\begin{abstract}
Soil Coefficient of Consolidation $(\mathrm{Cv})$ is a crucial mechanical parameter and used to characterize whether the soil undergoes consolidation or compaction when subjected to pressure. In order to define such a parameter, the experimental approaches are costly, time-consuming, and required appropriate equipment to perform the tests. In this study, the development of an alternative manner to estimate the Cv, based on Artificial Neural Network (ANN), was conducted. A database containing 188 tests was used to develop the ANN model. Two structures of ANN were considered, and the accuracy of each model was assessed using common statistical measurements such as the coefficient of determination $\left(\mathrm{R}^{2}\right)$, root mean square error (RMSE), and mean absolute error (MAE). In performing 600 simulations in each case, the ANN structure containing 14 neurons was statistically superior to the other one. Finally, a typical ANN result was presented to prove that it can be an excellent predictor of the problem, with a satisfying accuracy performance that yielded of $\mathrm{RMSE}=0.0614, \mathrm{MAE}=0.0415$, and $\mathrm{R}^{2}=0.99727$. This study might help in quick and accurate prediction of the $\mathrm{Cv}$ used in civil engineering problems.
\end{abstract}

Keywords: compression coefficient; Artificial Neural Networks; Vietnam; machine learning.

(C2020 Vietnam Academy of Science and Technology

\section{Introduction}

The coefficient of consolidation $(\mathrm{Cv})$ indicates the extent to which soil undergoes compaction or consolidation as it subjected to an increase in pressure, is known as one of the most important factors used for design and construction of buildings, roads, bridges, geotechnical structures, and any construction built on the soil or uses soil as a material (Dao et al., 2020b; Momeni et al., 2015; Pham et al., 2019b). This parameter is determined in the laboratory using the one-dimensional

*Corresponding author, Email: banglh@utt.edu.vn consolidation test or in the field using the Cone Penetration Piezocone Test. However, these tests are time consuming and costly, which might increase the cost of construction. Therefore, many efforts have been made to estimate this parameter by other alternative ways such as the $\mathrm{Cv}$ was determined through a correlation analysis with liquid limit and shrinkage limit (Sridharan and Nagaraj, 2004).

Nowadays, machine learning approaches have been successfully applied in various sub-domains to address many challenges (Dou et al., 2020; Ly and Pham, 2020; P. T. Nguyen 
et al., 2020a, 2020b; Qi et al., 2020b), including estimation of soil properties (M. D. Nguyen et al., 2019; Pham et al., 2019a). Such approaches, based on mathematical algorithms, possess the ability to provide the relationship between input variables and the output without knowing precisely the nature of the problems (T.-T. Le et al., 2020a; V.M. Le et al., 2020; L'heureux et al., 2017; Ly et al., 2020; P.T. Nguyen et al., 2020c). Therefore, they are able to handle complex problems and can treat datasets containing a large number of data points. Compared to traditional approaches, such as regression, weighted methods, numerical simulation, the use of machine learning is known as more practical and efficient (Qi et al., 2020a).

In this study, the main aim is to use an advanced and popular machine learning technique, namely Artificial Neural Networks (ANN) for accurate prediction of $\mathrm{Cv}$ of soil. Data of 188 soil samples collected from the national project of the coastal roads and highways of Ninh Binh - Hai Phong, Vietnam, were used to generate the training and testing datasets that were then used to build and validate the performance of the ANN model. Various quantitative validation indexes such as mean absolute error (MAE), root mean square error (RMSE), and coefficient of determination $\left(\mathrm{R}^{2}\right)$ were used to analyze and validate the predictive capability of the ANN model in both training and testing datasets. Modeling and data processing was carried out in the Matlab environment.

\section{Data collection and preparation}

In this study, 188 experimental results were used to construct the datasets for the machine learning model. The database contained 13 input variables, namely the depth of samples $(\mathrm{m})$, the clay content $(\%)$, the moisture content $(\%)$, the bulk density $\left(\mathrm{g} / \mathrm{cm}^{3}\right)$, the dry density $\left(\mathrm{g} / \mathrm{cm}^{3}\right)$, the specific gravity, the void ratio, soil porosity $(\%)$, degree of saturation of soil (\%), the liquid limit $(\%)$, the plastic limit $(\%)$, the plastic index (\%) and the liquidity index. The prediction target was the consolidation coefficient of soil $\left(10^{-3} \cdot \mathrm{cm}^{2} / \mathrm{s}\right)$. A brief introduction of the laboratory test and presentation of the variables could be found in (Das and Sobhan, 2013). The ranges and average values of the inputs are presented in Fig. 1. It should be noticed that the blue circles in these graphs represented the outliers of the dataset. The porosity, saturation, dry density, and liquidity index appeared to have the most outliers in the dataset.
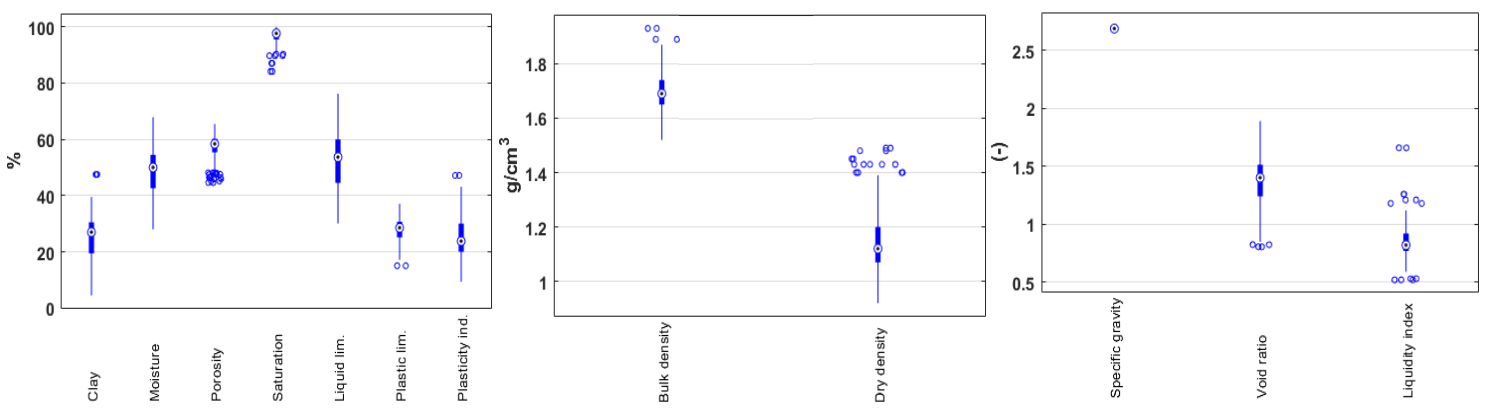

Figure 1. Statistical information of the input variables used in this study

In the present work, the dataset was split into two parts: the training and testing parts. The training dataset with 132 samples $(70 \%$ of the data) was used to train the ANN model, whereas the testing dataset with 56 samples
(30\% of the remaining data) used to verify the performance of the ANN model. Besides, it is worth noticing that the values of inputs and output were scaled to the range between 0 and 1 to reduce numerical bias, as suggested in 
(Ly et al., 2019d, 2019b, 2020; Pham et al., $2020 \mathrm{~b}$ ). After the simulations, these values were transformed to the raw space (or the initial space) to illustrate the results better.

\section{Method of Artificial Neural Networks}

Artificial neural networks (ANN) is an advanced and popular machine learning technique based on the biological neural network of the human brain (Panagiotis G. Asteris et al., 2019; Panagiotis G Asteris et al., 2019; Asteris and Mokos, 2019). Its structure includes three main layers, namely input layers, hidden layers, and output layers connected by nodes called neurons (Dao et al., 2019; Mohamad et al., 2012). Out of these layers, input layers represent the input parameters used for the construction of the models, hidden layers use activation functions to analyze the hidden relationship between input and output layers in data, and output layers are variables that need to be predicted (Armaghani et al., 2016; Mohamad et al., 2018; Pham et al., 2020a). The neurons in each layer were linked to the front and rear neurons with each associated weight (Khandelwal et al., 2018). There are two kinds of networked used in ANN, such as recurrent neural network and feed-forward neural network (FNN). Out of these, the FNN, based on the backpropagation algorithm (BP), is well-known networks used in many studies with good performance (Dao et al., 2020c; Mohamad et al., 2016; H.Q. Nguyen et al., 2020). Therefore, in this study, FNN was selected for the prediction of the $\mathrm{Cv}$. To validate the performance of FNN, different quantitative validation indexes, namely mean absolute error (MAE), root mean square error (RMSE), and coefficient of determination $\left(\mathrm{R}^{2}\right)$ were used. A detailed description of such measurements is presented in several previously published works. These indexes are expressed as follows (Chen et al., 2019; T.-T. Le et al., 2020b; Ly et al., 2019e, 2019c, 2019a; H.-L. Nguyen et al., 2019; Phong et al., 2019; Thanh et al., 2020):

$$
\begin{aligned}
& \mathrm{MAE}=\frac{1}{m} \sum_{i=1}^{m}\left(e_{i}-\bar{e}_{i}\right) \\
& \mathrm{RMSE}=\sqrt{\frac{1}{m} \sum_{i=1}^{m}\left(e_{i}-\bar{e}_{i}\right)^{2}} \\
& \mathrm{R}^{2}=1-\frac{\sum_{i=1}^{m}\left(e_{i}-\bar{e}_{i}\right)^{2}}{\sum_{i=1}^{m}\left(e_{i}-\bar{e}\right)^{2}}
\end{aligned}
$$

where $e_{i}$ is the actual output, $\bar{e}_{i}$ infers the predicted output, $\bar{e}$ infers the mean of the $e_{i}$ and $m$ infers the number of used samples.

\section{Results and Discussion}

\subsection{Selection of ANN structure}

The selection of suitable ANN structures is presented in this section. In general, many parameters could affect the accuracy of an ANN model, for instance, the number of hidden layers, the activation function, the cost function, and the number of neurons in the hidden layers. This work focused on the choice of the number of neurons in a single hidden layer ANN structure. Two choices were considered: a single hidden layer with 14 neurons (as suggested by Tamura (Tamura, 1997) or Nagendra (Nagendra, 1998) and a single hidden layer with 26 neurons (as suggested by Hecht-Nielsen (Hecht-Nielsen, 1987) or Gallant (Gallant and Gallant, 1993).

To this aim, 600 simulations were conducted (300 simulations for each case) to obtain reliable results, and the corresponding values are plotted (Fig. 2) under the form of probability density functions. The number of 300 simulations was verified by using statistical convergence indices (data not shown), which can be found in other previously published works (Dao et al., 2020a; Pham et al., 2020b). It is worth noticing that only the results of the testing datasets were shown, as they represented the 
accuracy of a machine learning algorithm in predicting the output.

Regarding the values of RMSE (Fig. 2a), it can be seen that a significant difference was observed between the two cases. Using 14 neurons in the hidden layer gave higher accuracy compared with 26 neurons. The mode of the first case was 7.721 at the value of RMSE $=0.1446$, whereas that of the second case was 6.222 at RMSE $=0.1851$. Moreover, the curve of 14 neurons was narrower than that in the case of 26 neurons, showing a lower level of fluctuation in performing the simulation. Similar to the previous criterion, the modes of MAE were 13.26 and 9.264 for 14 and 16 neurons at MAE values of 0.09216 and 0.1163 , respectively. It meant that the accuracy in

(a)

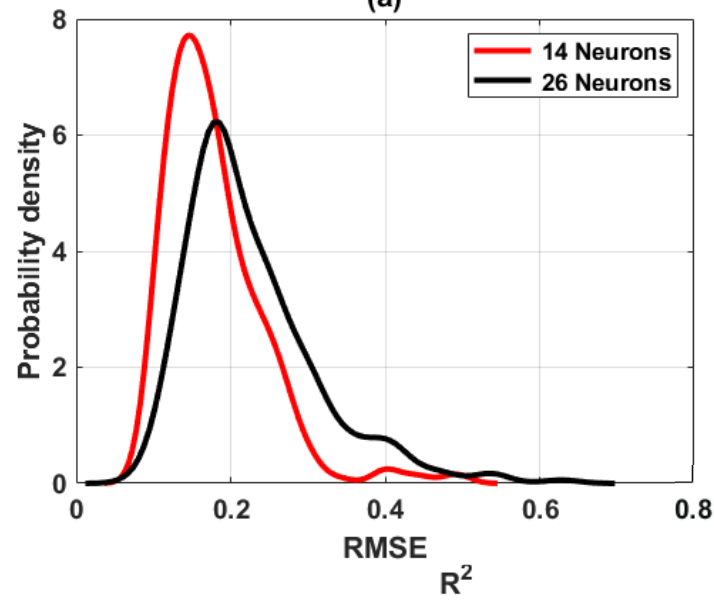

performing simulations with 14 neurons was superior to the case of 26 neurons. Again, the MAE curve in the case of 26 neurons was broader than that in the case of 14 neurons, representing the dispersion of results. Finally, the values of $\mathrm{R}$ showed that the highest mode (mode $=16.62$ ) in the case of 14 neurons could reach $\mathrm{R}=0.9658$, compared with the mode of 9.814 that gave $R=0.942$. Summary information over 300 simulations with respect to the two cases is presented in Table 1. It can be seen that predicting the $\mathrm{Cv}$ with 14 neurons was more accurate than 26 neurons, taking the min, average, max, and standard deviation values of RMSE, MAE, and R as criteria. In conclusion, the ANN structure with 14 neurons in a single hidden layer performed better than that of 26 neurons.

(b)

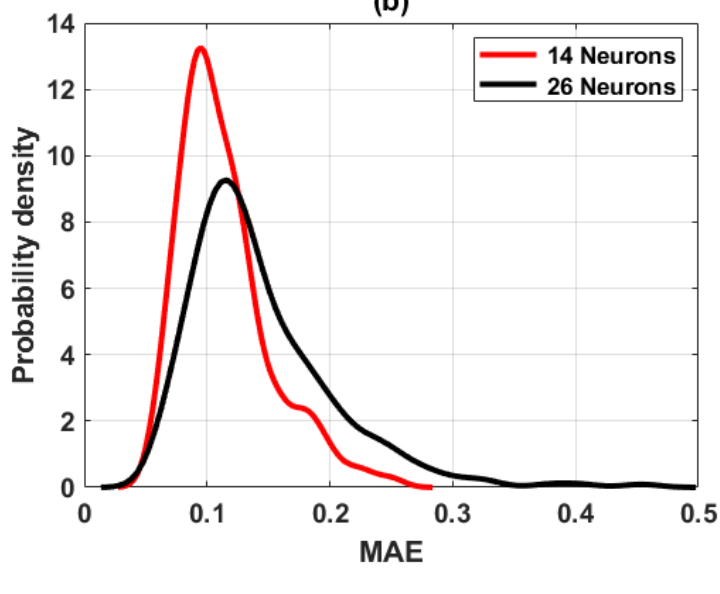

Figure 2. Probability density function over 300 simulations using ANN with 14 and 26 neurons for:

(a) RMSE; (b) MAE; and (c) $\mathrm{R}^{2}$

Table 1. Statistical information of the testing dataset for different cases over 300 simulations

\begin{tabular}{|l|r|r|r|r|}
\hline & \multicolumn{1}{|c|}{ Min. } & Average & \multicolumn{1}{c|}{ Max. } & ${ }^{\mathrm{a}}$ St.D. \\
\hline 14 neurons & & & & \\
\hline RMSE & 0.0878 & 0.1788 & 0.4943 & 0.0646 \\
\hline MAE & 0.057 & 0.114 & 0.254 & 0.0372 \\
\hline $\mathrm{R}^{2}$ & 0.5573 & 0.9416 & 0.9973 & 0.0494 \\
\hline 26 neurons & & & & \\
\hline RMSE & 0.0815 & 0.2262 & 0.628 & 0.0855 \\
\hline MAE & 0.0578 & 0.1434 & 0.4537 & 0.0587 \\
\hline $\mathrm{R}^{2}$ & 0.4213 & 0.9125 & 0.9909 & 0.0695 \\
\hline
\end{tabular}

${ }^{\mathrm{a}}$ St.D. $=$ Standard deviation

\subsection{Prediction capability}

The prediction capability of ANN using 14 neurons in the hidden layer is presented in this section. This is a typical result where the values of RMSE and MAE were the smallest, and the value of $\mathrm{R}$ was the highest. The results concerning the training dataset are presented in Fig. 3, whereas those of the testing dataset are plotted in Fig. 4. It can be observed that the experimental results were 
well correlated with the predicted output of ANN, and the values of error were small. Precisely, the values of RMSE, MAE, mean of error, and standard deviation error for the training part were 0.07308, 0.04588,

(a)

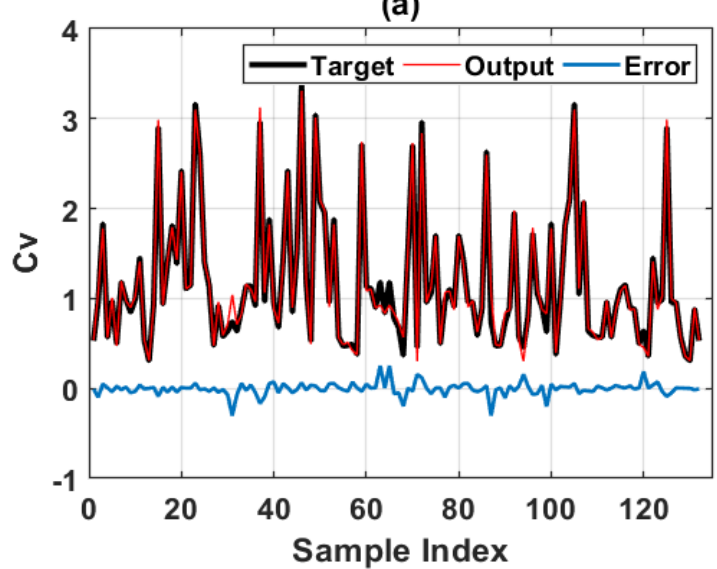

$-0.003365,0.07328$, respectively. Those of the testing dataset were $0.0614,0.0415$, -0.019 , and 0.0589 , respectively. In both cases, the values of error were frequented in the range of -0.1 to 0.1 .

(b)

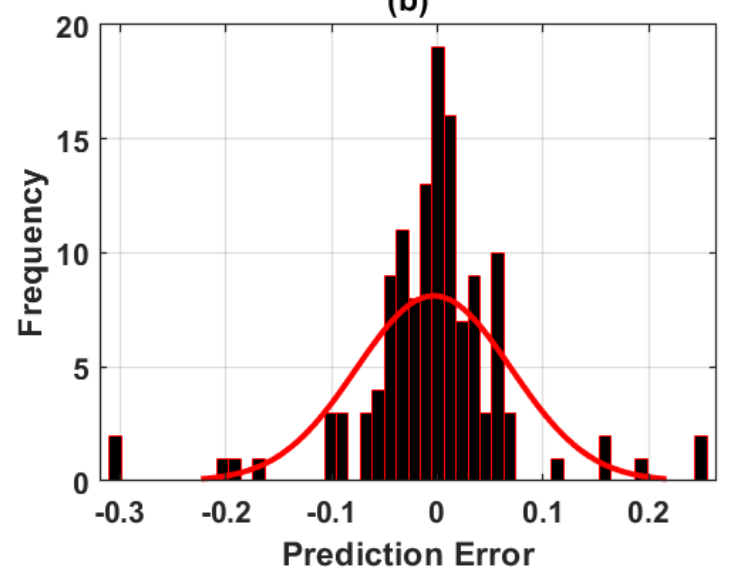

Figure 3. Target $\mathrm{Cv}$ versus predicted $\mathrm{Cv}$ for the training dataset using $\mathrm{ANN}$ with 14 neurons:

(a) according to the sample index; (b) histogram of error

(a)

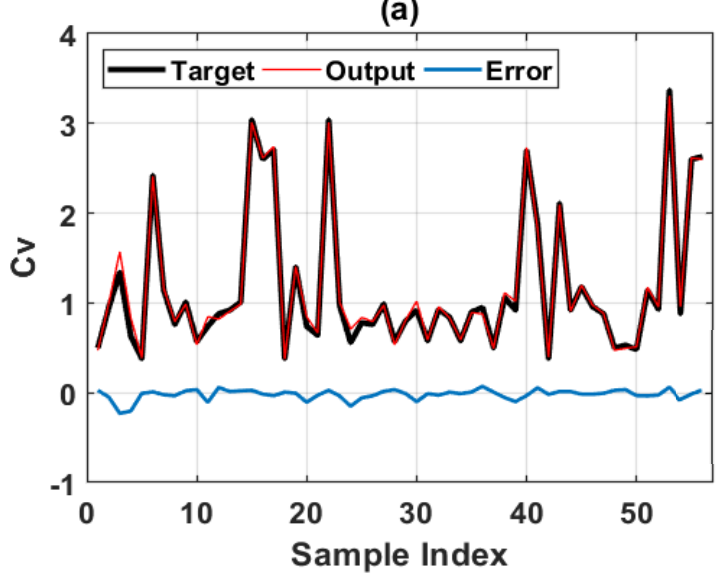

(b)

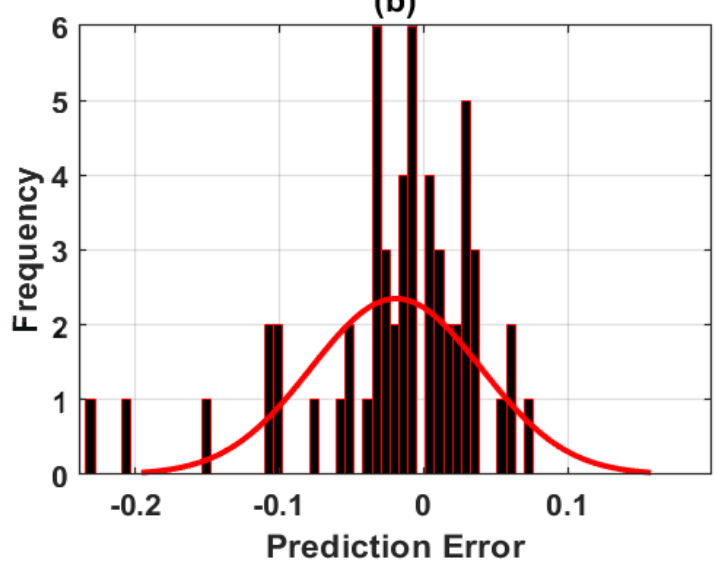

Figure 4. Target $\mathrm{Cv}$ versus predicted $\mathrm{Cv}$ for the testing dataset using ANN with 14 neurons:

(a) according to the sample index; (b) histogram of error

The two regression graphs comparing the correlation between the actual $\mathrm{Cv}$ and predicted $\mathrm{Cv}$ are given in Fig. 5 for the training (a) and testing datasets (b). Two equations relating the predicted and actual values of $\mathrm{Cv}$ were given, where " $y=0.99 * x+0.011 "$ was obtained for the training part, and " $\mathrm{y}=0.98 \mathrm{x}+0.037$ " was obtained for the testing dataset. The values of $\mathrm{R}$ were 0.999486 and 0.99727 for the training, testing parts, respectively. It could be concluded that the ANN algorithm is an excellent predictor in predicting the $\mathrm{CV}$ of soil. 
(a)

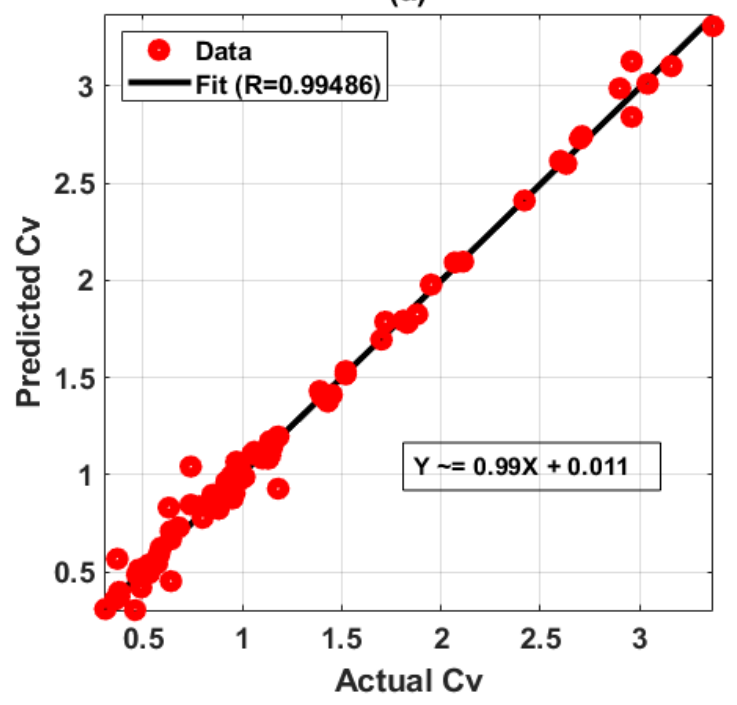

(b)

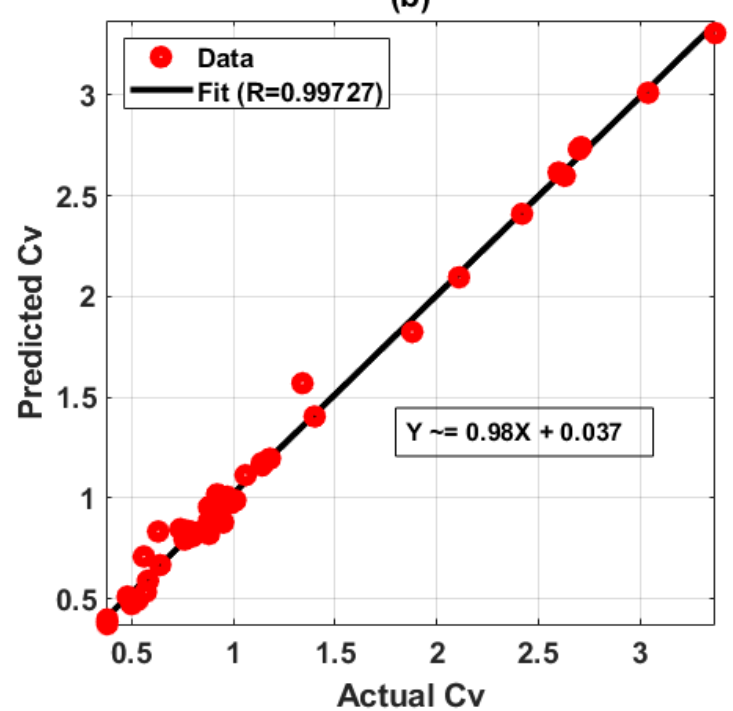

Figure 5. Regression graphs for ANN structure using 14 neurons in a single hidden layer:

(a) training dataset; (b) testing dataset

\section{Conclusions}

In this study, the development of an alternative manner to predict the $\mathrm{Cv}$ using Artificial Neural Network was addressed. To this aim, a database containing 188 experimental results was used for the training and validation phases of the proposed ANN model. The selection of appropriate structures of ANN was first considered, and the accuracy was assessed using the coefficient of determination, root mean square error, and mean absolute error. Results derived from 600 simulations showed that the ANN structure containing 14 neurons in the hidden layer was superior to the ANN with 26 neurons in the hidden layer. For illustration purposes, a typical result of ANN was presented with excellent accuracy of RMSE $=0.0614$, MAE $=0.0415$, and $\mathrm{R}=0.99727$. In conclusion, the ANN model with an appropriate choice of neurons can be an excellent predictor for quick assessing the $\mathrm{Cv}$ of soil.

\section{Acknowledgments}

This research is funded by Vietnam
National Foundation for Science and Technology Development (NAFOSTED) under grant number 105.08-2019.03

\section{References}

Armaghani D.J., Mohamad E.T., Hajihassani M., Yagiz S., Motaghedi H., 2016. Application of several non-linear prediction tools for estimating uniaxial compressive strength of granitic rocks and comparison of their performances. Engineering with Computers, 32, 189-206.

Asteris P.G., Mokos V.G., 2019. Concrete compressive strength using artificial neural networks. Neural Comput \& Applic. https://doi.org/10.1007/s00521-019-04663-2.

Asteris Panagiotis G., Apostolopoulou M., Skentou A.D., Moropoulou A., 2019. Application of artificial neural networks for the prediction of the compressive strength of cement-based mortars. Computers and Concrete, 24, 329-345.

Asteris Panagiotis G., Armaghani D.J., Hatzigeorgiou G.D., Karayannis C.G., Pilakoutas K., 2019. Predicting the shear strength of reinforced concrete beams using 
Artificial Neural Networks. Computers and Concrete, 24, 469-488. https://doi.org/10.12989/cac.2019.24.5.469.

Chen H., Asteris P.G., Jahed Armaghani D., Gordan B., Pham B.T., 2019. Assessing Dynamic Conditions of the Retaining Wall: Developing Two Hybrid Intelligent Models. Applied Sciences, 9, 1042. https://doi.org/10.3390/app9061042.

Dao D.V., Adeli H., Ly H.-B., Le L.M., Le V.M., Le T.-T., Pham B.T., 2020a. A Sensitivity and Robustness Analysis of GPR and ANN for High-Performance Concrete Compressive Strength Prediction Using a Monte Carlo Simulation. Sustainability, 12, 830. https://doi.org/10.3390/su12030830.

Dao D.V., Jaafari A., Bayat M., Mafi-Gholami D., Qi C., Moayedi H., Phong T.V., Ly H.-B., Le T.-T., Trinh P.T., Luu C., Quoc N.K., Thanh B.N., Pham B.T., 2020b. A spatially explicit deep learning neural network model for the prediction of landslide susceptibility. CATENA, 188, 104451. https://doi.org/10.1016/j.catena.2019.104451.

Dao D.V., Ly H.-B., Trinh S.H., Le T.-T., Pham B.T., 2019. Artificial Intelligence Approaches for Prediction of Compressive Strength of Geopolymer Concrete. Materials, 12, 983. https://doi.org/10.3390/ma12060983.

Dao D.V., Ly H.-B., Vu H.-L.T., Le T.-T., Pham B.T., 2020c. Investigation and Optimization of the C-ANN Structure in Predicting the Compressive Strength of Foamed Concrete. Materials, 13, 1072. https://doi.org/10.3390/ma13051072.

Das B.M., Sobhan K., 2013. Principles of geotechnical engineering. Cengage learning.

Dou J., Yunus A.P., Merghadi A., Shirzadi A., Nguyen H., Hussain Y., Avtar R., Chen Y., Pham B.T., Yamagishi H., 2020. Different sampling strategies for predicting landslide susceptibilities are deemed less consequential with deep learning. Science of The Total Environment, 720, 137320.

Gallant S.I., Gallant S.I., 1993. Neural network learning and expert systems. MIT press.
Hecht-Nielsen R., 1987. Kolmogorov's mapping neural network existence theorem, in: Proceedings of the International Conference on Neural Networks. IEEE Press New York, 11-14.

Khandelwal M., Marto A., Fatemi S.A., Ghoroqi M., Armaghani D.J., Singh T.N., Tabrizi O., 2018. Implementing an ANN model optimized by genetic algorithm for estimating cohesion of limestone samples. Engineering with Computers, 34, 307-317.

L'heureux A., Grolinger K., Elyamany H.F., Capretz M.A., 2017. Machine learning with big data: Challenges and approaches. IEEE Access, 5, 7776-7797.

Le T.-T., Pham B.T., Le V.M., Ly H.-B., Le L.M., 2020a. A Robustness Analysis of Different Nonlinear Autoregressive Networks Using Monte Carlo Simulations for Predicting High Fluctuation Rainfall, in: Micro-Electronics and Telecommunication Engineering. Springer, 205-212.

Le T.-T., Pham B.T., Ly H.-B., Shirzadi A., Le L.M., 2020b. Development of 48-hour Precipitation Forecasting Model using Nonlinear Autoregressive Neural Network, in: Ha-Minh C., Dao D.V., Benboudjema F., Derrible S., Huynh D.V.K., Tang A.M. (Eds.), CIGOS 2019, Innovation for Sustainable Infrastructure, Lecture Notes in Civil Engineering. Springer, Singapore, 1191-1196. https://doi.org/10.1007/978-981-15-0802-8_191.

Le V.M., Pham B.T., Le T.-T., Ly H.-B., Le L.M., 2020. Daily Rainfall Prediction Using Nonlinear Autoregressive Neural Network. Presented at the Micro-Electronics and Telecommunication Engineering: Proceedings of 3rd ICMETE 2019, Springer, 213-221.

Ly H.-B., Desceliers C., Le L.M., Le T.-T., Pham B.T., Nguyen-Ngoc L., Doan V.T., Le M., 2019a. Quantification of Uncertainties on the Critical Buckling Load of Columns under Axial Compression with Uncertain Random Materials. Materials, 12, 1828. https://doi.org/10.3390/ma12111828. 
Ly H.-B., Le L.M., Duong H.T., Nguyen T.C., Pham T.A., Le T.-T., Le V.M., Nguyen-Ngoc L., Pham B.T., 2019b. Hybrid Artificial Intelligence Approaches for Predicting Critical Buckling Load of Structural Members under Compression Considering the Influence of Initial Geometric Imperfections. Applied Sciences. 9, 2258. https://doi.org/10.3390/app9112258.

Ly H.-B., Le L.M., Phi L.V., Phan V.-H., Tran V.Q., Pham B.T., Le T.-T., Derrible S., 2019c. Development of an AI Model to Measure Traffic Air Pollution from Multisensor and Weather Data. Sensors, 19, 4941. https://doi.org/10.3390/s19224941.

Ly H.-B., Le T.-T., Le L.M., Tran V.Q., Le V.M., Vu H.-L.T., Nguyen Q.H., Pham B.T., 2019d. Development of Hybrid Machine Learning Models for Predicting the Critical Buckling Load of I-Shaped Cellular Beams. Applied Sciences, 9, 5458. https://doi.org/10.3390/app9245458.

Ly H.-B., Le T.-T., Vu H.-L.T., Tran V.Q., Le L.M., Pham B.T., 2020. Computational Hybrid Machine Learning Based Prediction of Shear Capacity for Steel Fiber Reinforced Concrete Beams. Sustainability, 12, 2709. https://doi.org/10.3390/su12072709.

Ly H.-B., Pham B.T., 2020. Prediction of Shear Strength of Soil Using Direct Shear Test and Support Vector Machine Model. The Open Construction and Building Technology Journal 14.

Ly H.-B., Pham B.T., Dao D.V., Le V.M., Le L.M., Le T.-T., 2019e. Improvement of ANFIS Model for Prediction of Compressive Strength of Manufactured Sand Concrete. Applied Sciences, 9, 3841. https://doi.org/10.3390/app9183841.

Mohamad E.T., Armaghani D.J., Hasanipanah M., Murlidhar B.R., Alel M.N.A., 2016. Estimation of air-overpressure produced by blasting operation through a neuro-genetic technique. Environmental Earth Sciences, 75, 174.

Mohamad E.T., Armaghani D.J., Momeni E., Yazdavar A.H., Ebrahimi M., 2018. Rock strength estimation: a PSO-based BP approach. Neural Computing and Applications, 30, 1635-1646.

Mohamad E.T., Hajihassani M., Armaghani D.J., Marto A., 2012. Simulation of blasting-induced air overpressure by means of artificial neural networks. Int. Rev. Model. Simul, 5, 2501-2506.

Momeni E., Nazir R., Armaghani D.J., Maizir H., 2015. Application of artificial neural network for predicting shaft and tip resistances of concrete piles. Earth Sciences Research Journal, 19, 85-93.

Nagendra S., 1998. Practical Aspects of Using Neural Networks: Necessary Preliminary Specifications. Technical Paper, GE Research and Development Center.

Nguyen H.-L., Pham B.T., Son L.H., Thang N.T., Ly H.-B., Le T.-T., Ho L.S., Le T.-H., Tien Bui D., 2019. Adaptive Network Based Fuzzy Inference System with Meta-Heuristic Optimizations for International Roughness Index Prediction. Applied Sciences, 9, 4715. https://doi.org/10.3390/app9214715.

Nguyen H.Q., Ly H.-B., Tran V.Q., Nguyen T.-A., Le T.-T., Pham B.T., 2020. Optimization of Artificial Intelligence System by Evolutionary Algorithm for Prediction of Axial Capacity of Rectangular Concrete Filled Steel Tubes under Compression. Materials, 13, 1205. https://doi.org/10.3390/ma13051205.

Nguyen M.D., Pham B.T., Tuyen T.T., Hai Yen H.P., Prakash I., Vu T.T., Chapi K., Shirzadi A., Shahabi H., Dou J., Quoc N.K., Bui D.T., 2019. Development of an Artificial Intelligence Approach for Prediction of Consolidation Coefficient of Soft Soil: A Sensitivity Analysis. The Open Construction and Building Technology Journal, 13. https://doi.org/10.2174/1874836801913010178.

Nguyen P.T., Ha D.H., Avand M., Jaafari A., Nguyen H.D., Al-Ansari N., Phong T.V., Sharma R., Kumar R., Le H.V., 2020a. Soft Computing Ensemble Models Based on Logistic Regression for Groundwater Potential Mapping. Applied Sciences, 10, 2469. 
Nguyen P.T., Ha D.H., Jaafari A., Nguyen H.D., Van Phong T., Al-Ansari N., Prakash I., Le H.V., Pham B.T., 2020b. Groundwater Potential Mapping Combining Artificial Neural Network and Real AdaBoost Ensemble Technique: The DakNong Province Casestudy, Vietnam. International Journal of Environmental Research and Public Health, 17, 2473.

Nguyen P.T., Ha D.H., Nguyen H.D., Van Phong T., Trinh P.T., Al-Ansari N., Le H.V., Pham B.T., Ho L.S., Prakash I., 2020c. Improvement of Credal Decision Trees Using Ensemble Frameworks for Groundwater Potential Modeling. Sustainability, 12, 2622.

Pham B.T., Nguyen M.D., Bui K.-T.T., Prakash I., Chapi K., Bui D.T., 2019a. A novel artificial intelligence approach based on Multi-layer Perceptron Neural Network and Biogeographybased Optimization for predicting coefficient of consolidation of soil. CATENA, 173, 302-311.

https://doi.org/10.1016/j.catena.2018.10.004.

Pham B.T., Nguyen M.D., Dao D.V., Prakash I., Ly H.-B., Le T.-T., Ho L.S., Nguyen K.T., Ngo T.Q., Hoang V., Son L.H., Ngo H.T.T., Tran H.T., Do N.M., Van Le H., Ho H.L., Tien Bui D., 2019b. Development of artificial intelligence models for the prediction of Compression Coefficient of soil: An application of Monte Carlo sensitivity analysis. Science of The Total Environment, 679, 172-184.

https://doi.org/10.1016/j.scitotenv.2019.05.061.

Pham B.T., Nguyen M.D., Ly H.-B., Pham T.A., Hoang V., Van Le H., Le T.-T., Nguyen H.Q., Bui G.L., 2020a. Development of Artificial Neural Networks for Prediction of Compression Coefficient of Soft Soil, in: HaMinh C., Dao D.V., Benboudjema F., Derrible S., Huynh D.V.K., Tang, A.M. (Eds.), CIGOS 2019, Innovation for Sustainable Infrastructure, Lecture Notes in Civil Engineering. Springer Singapore, 1167-1172.
Pham B.T., Nguyen-Thoi T., Ly H.-B., Nguyen M.D., Al-Ansari N., Tran V.-Q., Le T.-T., 2020b. Extreme Learning Machine Based Prediction of Soil Shear Strength: A Sensitivity Analysis Using Monte Carlo Simulations and Feature Backward Elimination. Sustainability, 12, 2339. https://doi.org/10.3390/su12062339.

Phong T.V., Phan T.T., Prakash I., Singh S.K., Shirzadi A., Chapi K., Ly H.-B., Ho L.S., Quoc N.K., Pham B.T., 2019. Landslide susceptibility modeling using different artificial intelligence methods: a case study at Muong Lay district, Vietnam. Geocarto International, $1-24$.

https://doi.org/10.1080/10106049.2019.1665715.

Qi C., Ly H.-B., Chen Q., Le T.-T., Le V.M., Pham B.T., 2020a. Flocculation-dewatering prediction of fine mineral tailings using a hybrid machine learning approach. Chemosphere, 244, 125450.

https://doi.org/10.1016/j.chemosphere.2019.125450. Qi C., Zhou W., Lu X., Luo H., Pham B.T., Yaseen Z.M., 2020b. Particulate matter concentration from open-cut coal mines: A hybrid machine learning estimation. Environmental Pollution, 114517.

Sridharan A., Nagaraj H.B., 2004. Coefficient of Consolidation and its Correlation with Index Properties of Remolded Soils. GTJ, 27, 469474. https://doi.org/10.1520/GTJ10784.

Tamura S., 1997. Method of determining an optimal number of neurons contained in hidden layers of a neural network.

Thanh T.T.M., Ly H.-B., Pham B.T., 2020. A Possibility of AI Application on Mode-choice Prediction of Transport Users in Hanoi, in: Ha-Minh, C., Dao, D.V., Benboudjema, F., Derrible, S., Huynh, D.V.K., Tang, A.M. (Eds.), CIGOS 2019, Innovation for Sustainable Infrastructure. Springer Singapore, Singapore, 1179-1184. https://doi.org/10.1007/978-981-15-0802-8_189. 